INTER-LEGERE

UMA PALAVRA SOBRE O SILÊNCIO: CONTEÚDOS DE GÉNERO PARA SOCIOLOGIA

NOS PCN, OCN E BNC

Andréa Osório

Flávio Sarandy

\title{
UMA PALAVRA SOBRE O SILÊNCIO: CONTEÚDOS DE GÊNERO PARA SOCIOLOGIA NOS PCN, OCN E BNC
}

\section{A WORD ABOUT A SILENCE: GENDER CONTENTS TO SOCIOLOGY \\ IN THE PCN, OCN AND BNC}

\author{
Andréa Osório ${ }^{1}$ \\ Flávio Sarandy ${ }^{2}$
}

\section{RESUMO}

Foram selecionados três documentos nacionais que dirigem orientações para conteúdos, práticas e didáticas específicas do conjunto das disciplinas da escola brasileira: os Parâmetros Curriculares Nacionais (PCN), as Orientações Curriculares Nacionais (OCN) e a Base Nacional Comum Curricular (BNC). Ao analisarmos os conteúdos relativos à área de Sociologia, percebemos um silêncio quanto às questões de gênero. Embora o conceito não esteja totalmente ausente, ele parece incorporar, em todos os documentos, menos uma preocupação teórico-metodológica do que uma espécie de dado reificado da realidade: o de que homens e mulheres são diferentes, sem questionar essa afirmação nem as bases nas quais ela é efetuada.

Palavras-chave: PCN. OCN. BNC. Gênero. Ensino de Sociologia.

\section{ABSTRACT}

Three national documents driving guidelines for content, practices and specific didactics of all the disciplines of Brazilian schools were selected: the National Curriculum Parameters (PCN), the National Curriculum Guidelines (OCN) and the National Curriculum Common Bases (BNC). When analyzing the contents relating to the area of Sociology, we noticed a silence to gender issues. Although the concept is not entirely absent, it seems to embody, in all documents, less theoretical and

\footnotetext{
${ }^{1}$ Doutora em Antropologia e Professora Adjunta na UFF.

${ }^{2}$ Mestre em Sociologia e Professor Assistente na UFF.
} 
INTER-LEGERE

UMA PALAVRA SOBRE O SILÊNCIO: CONTEÚDOS DE GÊNERO PARA SOCIOLOGIA

NOS PCN, OCN E BNC

Andréa Osório

Flávio Sarandy

methodological concerns than a kind of reified given reality: that men and women are different, without questioning that statement nor the basis on which it is made.

Keywords: PCN. OCN. BNC. Gender. Sociology teaching.

\section{INTRODUÇÃO}

O objetivo do presente trabalho é analisar como a questão de gênero tem sido abordada nos documentos que orientam o ensino de Sociologia nacionalmente na escola brasileira. Foram pesquisados os Parâmetros Curriculares Nacionais para o Ensino Médio (PCN) - Parte I (Bases Legais) e Parte IV (Ciências Humanas e suas Tecnologias); as Orientações Curriculares Nacionais para o Ensino Médio (OCN), volume 3 - Ciências Humanas e suas Tecnologias; e a Base Nacional Comum Curricular (BNC).

O intuito não é uma reflexão total do que os documentos propõem para o ensino de Sociologia, mas um recorte sobre o que o ensino de Sociologia, conforme ali delineado, propõe em termos de debate acerca das relações de gênero no Brasil. Embora este seja um tema multidisciplinar, é uma área consolidada de estudos nas Ciências Sociais e, desse ponto de vista, entende-se que tal debate deveria estar alocado (também e não tão somente) nos conteúdos sociológicos.

O silêncio quanto ao tema é, com perdão do trocadilho, gritante. Nos PCN, a maior parte do debate está alocada nos Temas Transversais - Orientação Sexual. Nas OCN, há muito pouco a respeito e na parte relativa à Sociologia encontra-se somente a indicação de que este é um dos conteúdos que podem ser tratados na disciplina. Nas BNC, o documento mais recente dos três, ao contrário dos anteriores, identifica-se a categoria gênero perpassando disciplinas tão distintas quanto Artes, Biologia, Educação Física e Sociologia, com uma coerência que faz dele uma proposta mais homogênea do que as demais. Contudo, peca nos mesmos pontos.

Seguimos a sugestão analítica de Gandelman (2003), que percebe nos conteúdos de Orientação Sexual dos PCN uma oscilação entre gênero como uma categoria que nomeia a diferença entre homens e mulheres, recaindo, portanto, nos 
INTER-LEGERE

UMA PALAVRA SOBRE O SILÊNCIO: CONTEÚDOS DE GÉNERO PARA SOCIOLOGIA

NOS PCN, OCN E BNC

Andréa Osório

Flávio Sarandy

aspectos biológicos dos quais tentava justamente se afastar, e uma constante afirmação da natureza social dessa diferença. Com base nos recentes debates suscitados no bojo do que tem sido chamado de teorias queer, questionamos se um tal uso de fato permite que pensemos sobre gênero.

\section{GÊNERO}

Gênero é uma categoria que tenta dissociar aspectos socialmente construídos a respeito da feminilidade e da masculinidade de sua pretensa determinação biológica, mas que também permite questionar a associação entre sexo biológico, gênero socialmente constituído e práticas afetivo-sexuais. O gênero é sempre múltiplo, constituído na relação (ou confrontação) com Outros, permeada por aspectos como hierarquia, dominação e poder.

Conforme Scott (1989, p. 1-2),

[...] as feministas começaram a utilizar a palavra "gênero" mais seriamente, no sentido mais literal, como uma maneira de referir-se à organização social da relação entre os sexos. [...] No seu uso mais recente, o "gênero" parece ter aparecido primeiro entre as feministas americanas que queriam insistir no caráter fundamentalmente social das distinções baseadas no sexo. A palavra indicava uma rejeição ao determinismo biológico implícito no uso de termos como "sexo" ou "diferença sexual". O "gênero" sublinhava também o aspecto relacional das definições normativas da feminilidade. [...] Utilizaram o termo "gênero" para introduzir uma noção relacional no nosso vocabulário analítico. Segundo esta opinião, as mulheres e os homens eram definidos em termos recíprocos e nenhuma compreensão de qualquer um poderia existir através de estudo inteiramente separado.

De fato, se tomarmos a definição de gênero de Scott (1989) conforme a apresentamos acima, deixamos de fora toda uma gama de debates recentes que têm sido classificados como teorias queer e que permitiram, nas últimas décadas, uma abordagem mais crítica do próprio conceito de gênero, como também das múltiplas relações e inflexões entre gênero, sexo, sexualidades, performances, 
UMA PALAVRA SOBRE O SILÊNCIO: CONTEÚDOS DE GÉNERO PARA SOCIOLOGIA

NOS PCN, OCN E BNC

Andréa Osório

Flávio Sarandy

afetividades, normas, desvios, produção de conhecimento e produção de sujeitos, entre outros.

Louro (2001), em uma proposta de uso das teorias queer na educação, apresenta um balanço da importância desses novos estudos em termos epistemológicos. Segundo ela, as teorias queer propõem um rompimento com a lógica binária masculino/feminino, homem/mulher e seus efeitos políticos em termos de hierarquizações, dominações, exclusões e classificações. A interdependência das categorias que nomeiam homens e mulheres, homossexuais e heterossexuais forma um quadro de referências em que a oposição demarca identidades e diferenças. Como opostos, um deles não pode ser exterminado sem a necessária decadência do seu Outro.

Caminhando para as questões de normatividade, Louro (2001) indica que as teorias queer apontam para a norma (heterossexualidade) como um processo que foi naturalizado. A crítica é orientada, portanto, não apenas às representações sociais que naturalizam construções socioculturais historicamente dadas, mas à própria oposição enunciada. Uma proposta pós-identitária surge, na qual a fluidez marca tanto o gênero quanto a sexualidade. A multiplicidade passa a ser possível, desatando o nó do binarismo. Em outros termos, emergem múltiplas formas de masculinidades e feminilidades, de corpos, de práticas sexuais, de afetos.

\section{PCN}

Os Parâmetros Curriculares Nacionais (PCN) constituem documentos de caráter normativo, porém sem força de lei, que pretenderam padronizar o ensino formal no Brasil, estabelecendo referências e critérios para a organização curricular da Educação Básica e para a prática pedagógica. Esses documentos, que integram a Reforma Educacional da década de 1990, começaram a ser elaborados em 1995 e foram concluídos em 1997 sob a gestão de Paulo Renato Souza à frente do Ministério da Educação, durante o governo Fernando Henrique Cardoso, sob a coordenação de Guiomar Namo de Mello. Já as Diretrizes Curriculares Nacionais 
(DCN) são as normas obrigatórias para a Educação Básica que orientam o planejamento curricular das escolas e dos sistemas de ensino, normalmente formuladas como Resoluções do Conselho Nacional de Educação (CNE).

Nos PCN, gênero é uma categoria pouco utilizada, às vezes substituída por "mulheres" ou "mulheres e homens", subsumindo a todos nas relações de gênero, já que as abordagens não parecem se referir a determinismos biológicos, mas sempre a realidades socialmente constituídas.

Quando tentamos localizar passagens concernentes às relações de gênero, encontramos muito pouco debate nos documentos que dizem respeito à área de Sociologia. Partimos, então, para uma observação da área de História que apresenta mais passagens nas quais as relações de gênero são incluídas. Descontentes com nossa descoberta, alargamos o escopo para os Temas Transversais, nos quais finalmente encontramos o "lar" das relações de gênero no Ensino Médio brasileiro, na Reforma Educacional do período: a Orientação Sexual.

Comparando-se as áreas de Sociologia e História, por um lado, e Orientação Sexual, por outro, percebemos que, nas primeiras, as questões de gênero aparecem relacionadas ao exercício da cidadania e como um dado da realidade social a ser levado em consideração nas análises. O foco está na questão da igualdade de direitos. Há uma reflexão sobre a construção de uma cidadania que seja inclusiva, isto é, que indique as diferenças sociais entre os cidadãos e garanta-lhes uma igualdade em termos de direitos, sem prejuízo para tais diferenças. A mesma abordagem foi encontrada nos Temas Transversais - Ética. Na Orientação Sexual, são as relações de gênero em si que aparecem conjuntamente à sexualidade.

O PCN de Sociologia, Antropologia e Política não faz nenhuma menção direta à categoria gênero ou à necessidade de se pensar as relações de gênero na sociedade brasileira e no mundo. Tal conteúdo está presente na seção dedicada ao ensino de História e em mais de um momento. De fato, isso não chega a surpreender, na medida em que a historiografia, feminista ou não, incorporou as questões de gênero de uma forma menos sectária do que as Ciências Sociais, em que as relações de gênero são uma subárea temática. 
De um modo geral, nos PCN de História, as mulheres (não os homens) aparecem ao lado de crianças e etnias como objeto (não sujeitos) de estudo da vida cotidiana. A categoria gênero é às vezes substituída pela ideia de "mulheres", como se todas as minorias de direito formassem um mesmo problema ou objeto de estudo. A nomeação constante das "mulheres" em oposição aos homens, apesar de Ihes dar alguma visibilidade, contém armadilhas. Incluímos na análise o binômio homens/mulheres como um discurso sobre o gênero porque este, nos PCN, oscila entre natureza e cultura. É, portanto, na própria narrativa discursiva, que se pretende crítica, que encontramos as armadilhas de fundo epistemológico e político: reifica-se o que se pretende desnaturalizar e incorre-se no mesmo risco de violência simbólica, quando sujeitos, transfigurados em objetos, têm sua voz silenciada pelos porta-vozes que se apresentam como seus representantes ou tradutores.

Gandelman (2003) fez uma análise dos conteúdos de gênero na parte sobre Orientação Sexual dos Temas Transversais dos PCN, apontando para a importância do debate e criticando alguns dos caminhos adotados para a sua abordagem. Embora a categoria seja definida ali, alerta a autora, o primeiro problema surge quando se observa que essa definição faz parecer que não há embates teóricos no campo dos estudos de gênero. Mais grave, a autora sugere que o documento tenta abordar as relações de gênero como socialmente constituídas, porém recai sistematicamente em um "fundacionalismo biológico", numa perspectiva psicologizante e, como consequência, numa naturalização da oposição feminino/masculino que deveria, justamente, ser questionada.

Em vez, portanto, de implementar um questionamento e uma visão crítica das relações de gênero, o que os PCN produzem refere-se a uma percepção de gênero como constituído por dois universos binários separados, homens e mulheres, reificando o gênero como algo relacionado ao aparato biológico: ser homem, ser mulher. As diferenças emergem como essencializadas, ao mesmo tempo que se professa sua origem social.

Essa oscilação é percebida por Altmann (2001) com relação, também, à própria noção de sexualidade nos PCN - Temas Transversais/Orientação Sexual. 
Efetuando uma análise tanto da Orientação Sexual quanto da área de Educação Física, em que parte desses conteúdos transversais deveria ser trabalhada, a autora indica que a sexualidade aparece no documento "sob o ponto de vista biológico, atrelada às funções hormonais" (ALTMANN, 2001, p. 581), e que, embora os PCN advoguem uma construção histórica e sociocultural das práticas sexuais, o corpo permanece não apenas como o lócus da sexualidade, mas também como um universal encontrado em todas as sociedades e culturas.

[A] dimensão histórica é pensada como sendo construída em cima de algo naturalmente dado. Em outras palavras, a sexualidade e o sujeito são pensados como essências sob as quais há um investimento da cultura (ALTMANN, 2001, p. 581).

As oscilações entre natural e social não perpassam apenas o uso que os PCN fazem das noções de gênero e sexualidade, mas são observadas também no tratamento dado ao próprio corpo. Ele é parte dos conteúdos de Biologia e Educação Física, um ator importante na Orientação Sexual, mas invisível nos conteúdos de Sociologia e História, por exemplo. Apesar de Altmann (2001, p. 581) indicar que os PCN "insinuam uma crítica à naturalidade do corpo através da afirmação de variações culturais", a própria autora aponta como ele é tomado recorrentemente como uma "entidade natural" e a sua ausência nas disciplinas de Ciências Humanas apenas segue essa lógica.

Retornando às relações de gênero, Gandelman (2003) ressalta que elas são sobrepostas a questões de alteridade. Quando isso ocorre, alerta a autora, o texto passa a discorrer sobre a tolerância, a compreensão do outro e a prevenção da discriminação e da violência, dando às relações de gênero um tratamento análogo ao de minorias. As mulheres se tornam um Outro dos homens, ambos os polos uniformizados internamente e diferentes apenas entre si.

Outra ausência pungente notada pela autora é o conflito. As relações de gênero se tornam desprovidas de sujeitos históricos que efetivamente as constroem e das relações sociais que as criam e às suas representações. Omitem-se, portanto, também, as relações de poder constituintes das relações de gênero - e, poderíamos 
INTER-LEGERE

UMA PALAVRA SOBRE O SILÊNCIO: CONTEÚDOS DE GÊNERO PARA SOCIOLOGIA

NOS PCN, OCN E BNC

Andréa Osório

Flávio Sarandy

acrescentar, a historicização dos movimentos sociais relacionados. Relações de poder, ela demonstra com o apoio da literatura feminista especializada, não criam e reificam apenas relações de gênero assimétricas, mas criam, seguindo Butler (2003), a própria noção de uma diferença sexual e sua relevância, gerando, portanto, "aparatos produtores de corpos e sexualidades" (GANDELMAN, 2003, p. 215).

OCN

As Orientações Curriculares Nacionais (OCN) constituem documentos que pretenderam responder ao fracasso dos PCN como política governamental e como referência normatizante da educação na sociedade brasileira. Elaborados a partir de seminários de análise das DCN e PCN, organizados pelo MEC em 2004 e publicados em 2006 no governo Luiz Inácio Lula da Silva, tiveram como autores Amaury Cesar Moraes, Elisabeth Guimarães e Nelson Dacio Tomazi.

Embora Gandelman (2003) tenha analisado apenas uma parte dos PCN, acreditamos que suas críticas podem ser generalizadas, em maior ou menor medida, tanto para outros itens dos PCN quanto para as OCN e BNC, conforme aqui recortados. Nas Orientações Curriculares para o Ensino Médio (OCN), volume 3 Ciências Humanas e suas Tecnologias, que trata de Filosofia, Geografia, História e Sociologia, gênero é uma categoria que aparece menos na área de Sociologia do que na de História. Nessa área, a categoria aparece, por exemplo, no seguinte trecho:

\begin{abstract}
Entende-se o trabalho na sua diversidade social, econômica, política e cultural, pois o trabalho não se refere somente às formas de produzir formalmente e historicamente aceitas nas diversas sociedades históricas, tais como a escravidão, a servidão e o trabalho assalariado, mas também ao trabalho relacionado à esfera doméstica, à prática comunitária, às manifestações artísticas e intelectuais, à participação nas instâncias de representação políticas, trabalhistas, comunitárias e religiosas. Essas diferentes formas de produzir e organizar a vida individual e coletiva intercambiam-se com diversas perspectivas ou abordagens. Dentre elas podem-se
\end{abstract}


destacar as de gênero (a participação das mulheres e dos homens nas relações entre trabalho formal, informal e doméstico); de parentesco ou de comunidade (posição dos membros na hierarquia da família e da comunidade relacionados a sua ocupação profissional); de geração (as transformações históricas na relação entre o trabalho formalmente aceito em uma sociedade e o trabalho infantil, além do trabalho como formação educativa nas dimensões professor/aluno, mestre/aprendiz, entre outras); e de poder (tensões e conflitos entre os diferentes agentes sociais, profissionais e políticos) (OCN, 2006, v. 3, p. 76).

As chaves de análise do universo do trabalho apresentadas no excerto acima são conceitos característicos das análises de Sociologia e Antropologia: gênero, geração, poder, comunidade e parentesco. Esta última, inclusive, é um dos pilares de formação da Antropologia e fundamenta boa parte das pesquisas da chamada teoria clássica, muito embora venha como sinônimo de comunidade na passagem transcrita. Gênero aparece explicitamente como sinônimo de homens e mulheres, incluindo-se uma reflexão sobre o trabalho doméstico (feminino) como trabalho de fato, ponto de luta dos movimentos de mulheres. Não obstante, como o excerto se refere a uma análise do conceito de trabalho, a categoria gênero é utilizada em conjunto com este e não com os demais conceitos apresentados (geração, parentesco, comunidade e poder).

Quando se passa para a seção específica de Sociologia da OCN, encontra-se apenas um momento em que a categoria gênero é utilizada:

Outros temas que podem ser incluídos em um programa: questão racial, etnocentrismo, preconceito, violência, sexualidade, gênero, meio ambiente, cidadania, direitos humanos, religião e religiosidade, movimentos sociais, meios de comunicação de massa, etc. (OCN, 2006, v. 3, p. 121).

O trecho está inserido numa reflexão sobre a pertinência ou impertinência do ensino da Sociologia de viés temático. Assim, gênero emerge como um tema possível de trabalho em sala de aula, mas não como um tema necessário. Há uma diferença clara na abordagem da seção de História e da seção de Sociologia: na primeira, gênero é uma categoria de análise da realidade social presente ou 
INTER-LEGERE

UMA PALAVRA SOBRE O SILÊNCIO: CONTEÚDOS DE GÉNERO PARA SOCIOLOGIA

NOS PCN, OCN E BNC

Andréa Osório

Flávio Sarandy

passada; na segunda, gênero é um tema de trabalho e fica a cargo do professor a opção de utilizá-lo, se optar, antes, por uma abordagem temática. A desvalorização do conceito fica explícita.

\section{BNC}

Segundo o Ministério da Educação, a Base Nacional Comum Curricular (BNC)

vai deixar claros os conhecimentos essenciais aos quais todos os estudantes brasileiros têm o direito de ter acesso e se apropriar durante sua trajetória na Educação Básica, ano a ano, desde o ingresso na Creche até o final do Ensino Médio. Com ela os sistemas educacionais, as escolas e os professores terão um importante instrumento de gestão pedagógica e as famílias poderão participar e acompanhar mais de perto a vida escolar de seus filhos ${ }^{3}$.

Trata-se de documento previsto na legislação educacional brasileira e segue a mesma lógica dos documentos discutidos anteriormente, a saber, a de padronizar a organização curricular brasileira, no caso atual, pela adoção do modelo de organização curricular por competências.

A Base Nacional Comum Curricular foi divulgada pelo MEC em torno de setembro de 2015 e forma o conjunto mais recente de documentos aqui analisados. Nesse sentido, acreditamos que, a despeito de seu objetivo ser distinto do almejado pelos documentos anteriores, ele poderia ter incorporado as críticas efetuadas aos $P C N$ e às $\mathrm{OCN}$. No que tange às relações de gênero, foi interessante observar como a categoria passa a nomear o que era descrito nos demais documentos como "mulheres" ou "mulheres e homens". Porém, a natureza das críticas de Gandelman (2003) não nos parece ter sido superada.

$\mathrm{Na}$ apresentação do "componente curricular Sociologia", o documento alerta que "assim como homens e mulheres fazem a sociedade, a sociedade faz os homens e as mulheres" (BNC, 2015, p. 297), apontando para os fatores sociais

3 Disponível em: <http://basenacionalcomum.mec.gov.br/\#/site/base/o-que>. Acesso em: 16 nov. 2015. 
como relevantes para os indivíduos. Não obstante, esses indivíduos binariamente genderizados como homens ou mulheres não são levados a questionar que as categorias homens/mulheres são tão socialmente construídas como a sociedade que eles constroem.

Mais adiante, o documento informa que "os mais importantes [conceitos sociológicos básicos] são: fato social, classes sociais, ações e relações sociais, igualdade/desigualdade e diversidade" (BNC, 2015, p. 298). Gênero e relações de gênero não são considerados nem básicos nem importantes e presumimos que sejam componentes invisibilizados de "relações sociais", desigualdades e diversidade. Esta última foi incluída seguindo a lógica dos PCN de alocar gênero como uma questão de tolerância à diversidade na sociedade.

Na mesma página 298, a violência contra a mulher, o racismo e a homofobia emergem como "debates atuais", junto com "movimentos sociais por direitos de minorias", o que sugere uma consolidação da abordagem dos PCN na qual as mulheres são consideradas minorias junto com as sexualidades não heteronormativas. Seguindo Gandelman (2003), sugerimos que o documento mantém um viés androcêntrico no qual o espaço de fala privilegiado é o dos homens brancos heterossexuais, que se constituem como uma maioria frente a outras identidades de gênero, sexuais e étnico-raciais.

Quando o texto passa aos objetivos de aprendizagem, apenas duas vezes a categoria gênero aparece. Ela não é alocada mais como marcador social de "diversidade cultural", como nos PCN, mas permanece associada à divisão do trabalho segundo o sexo, que traria "implicações para as relações de gênero". Parece-nos que a própria dimensão de uma divisão segundo o sexo (biológico) deveria ser revista, pois, como aponta Butler (2003), a diferença sexual e sua relevância são criadas por relações de poder e não se constituem como um dado biológico neutro.

Por outro lado, as BNC avançam em incluir ao menos um item acerca da "perspectiva socioantropológica sobre sexo, sexualidade e gênero", sugestão que estava totalmente ausente dos documentos anteriores. Também foi incluída, vale 
INTER-LEGERE

UMA PALAVRA SOBRE O SILÊNCIO: CONTEÚDOS DE GÊNERO PARA SOCIOLOGIA

NOS PCN, OCN E BNC

Andréa Osório

Flávio Sarandy

notar, a sugestão de reflexão sobre novos movimentos sociais, abordando-se, entre outros, o feminismo e o "movimento pelos direitos dos homossexuais", sem aludir à sua multiplicidade interna, em especial às questões pós-identitárias colocadas pelos debates sobre o universo trans e as teorias queer.

\section{UMA PALAVRA SOBRE O SILÊNCIO}

Um currículo não é um conceito, mas uma construção cultural e um ato de poder que fundamenta o modo de se organizar uma série de práticas educativas que vão muito além da delimitação de componentes curriculares e da própria sala de aula, servindo ao empoderamento dos sujeitos tanto quanto à sua dominação. $O$ silêncio sobre determinados conteúdos - sua ausência - acaba por funcionar também como base de um currículo que sempre e necessariamente refletirá relações de dominação na sociedade. Tal é o caso de que trata o presente texto.

Se gênero emerge em alguns lugares fora da Orientação Sexual, por que seu debate é minimizado e, dependendo do documento, silenciado no âmbito do ensino de Sociologia? Acreditamos que isso se deva menos às orientações políticas educacionais do que às orientações do campo acadêmico sociológico brasileiro e de suas dinâmicas internas. Por um lado, se o ensino de Sociologia tem se constituído como uma área própria dentro da Sociologia, e não da Educação ou da Pedagogia, as interseções entre classe, gênero, sexualidade, relações étnico-raciais, entre outras, e ensino de Sociologia não são, ainda, uma produção consolidada. Isso faz parecer, à primeira vista, que o ensino da disciplina é algo homogêneo, uniforme e que não apresenta dilemas, conflitos ou transgressões internas - assim como não esclarece as tensões geradas na produção do conhecimento acadêmico e do conhecimento escolar. Por outro lado, "diz" algo sobre temas valorizados e temas marginalizados nas Ciências Sociais brasileiras.

O ensino da Sociologia como disciplina do Ensino Médio brasileiro ainda sofre com um forte viés bacharelesco, em que predomina a reprodução dos modelos curriculares e de práticas de ensino típicos da formação profissional acadêmica em 
INTER-LEGERE

UMA PALAVRA SOBRE O SILÊNCIO: CONTEÚDOS DE GÊNERO PARA SOCIOLOGIA

NOS PCN, OCN E BNC

Andréa Osório

Flávio Sarandy

nível superior. As preocupações que parecem prevalecer nos que pensam os currículos e nos autores dos documentos referidos neste artigo ainda são demasiadamente teóricas, relacionadas às abstrações conceituais, com pouca ou nenhuma transformação que permita que o conhecimento científico acumulado pelas Ciências Sociais se faça conhecimento escolar significativo para uma educação emancipadora.

O que temos, ainda, é a tentativa mecânica de migrar as Ciências Sociais à escola, sem o trabalho necessário de construção de estratégias que permitam deslocamentos, intermediações, atualizações e traduções. Por vezes, pode-se observar que a ênfase nas categorias teóricas e no debate conceitual próprio da formação acadêmica reflete-se em tratamentos rasos quando dirigidos à construção curricular da disciplina do Ensino Médio. A esse contexto soma-se, por parte da comunidade acadêmica, o receio da politização excessiva ou da partidarização política da disciplina. Nesse movimento, perdem-se as questões mais relevantes para a reorganização cognitiva que a disciplina pode proporcionar e que é seu fim último. Advogamos que será justamente no movimento inverso, de (re)construção teórica do conhecimento escolar fundado no debate mais atual produzido no campo científico, que encontraremos novas orientações ao ensino disciplinar e transdisciplinar por meio das quais questões públicas relevantes encontrarão caminhos de esclarecimento por ação pedagógica e formativa de caráter político amplo.

Como apontamos antes, por exemplo, a Sociologia insiste em reproduzir a noção de uma divisão do trabalho segundo o sexo, que, não obstante, traria consequências para as relações de gênero. A utilização de ambos os conceitos como se fossem sinônimos apenas apaga os debates sobre gênero ao naturalizar um dado biológico como social, nunca o contrário. Por que docentes de Sociologia não alertam seus alunos de que esse debate foi constituído, a partir de Durkheim, Weber e Marx, num momento histórico em que o feminismo era apenas nascente ou não existia? Por que historicizar certas ideias e não outras? Por que eleger certos conceitos como supérfluos ou de menor importância? Por que analisar uma fração 
da realidade social a partir da Sociologia e outra a partir do senso comum? Que tipo de Sociologia se ensina desse modo?

Com essas perguntas, não tentamos depositar sobre o docente de Ensino Médio, como tem sido o caso nas recentes políticas educacionais brasileiras, todo o ônus pelo desempenho satisfatório discente. Ao contrário, questionamos antes o próprio campo sociológico acadêmico, que é constituído não apenas pela universidade formadora de docentes, mas pelas escolas e pelos editores e autores de livros didáticos, entre outros.

Aprender um conceito é apreender o seu significado e sentidos, compreender sua inserção na história, sua fortuna crítica e a "experiência articulada" perante constrições sociais de que ele é resultante e de lutas as quais integra, como nos ensina Raymond Williams (1979), tanto quanto ser capaz de mobilizá-lo na análise de fenômenos sociais, isto é, pensar com o conceito e sobre ele. Não basta, e não somente para o ensino na Educação Básica, que conceitos sejam "transmitidos" como referidos às "coisas", reificados e naturalizados. É necessário acrescer ao ensino de um conceito as lutas por sua definição, construção e afirmação.

Compreendemos que o objetivo do ensino de Sociologia na Educação Básica é desenvolver uma nova atitude cognitiva, um modo específico de olhar e compreender a realidade social e humana, a apropriação de uma abordagem da experiência humana. Essa atitude cognitiva é definida pelos modos de raciocínio desenvolvidos no campo científico das Ciências Sociais: um olhar que estranha o real, pois compreende que ele não é um dado; que desnaturaliza os fenômenos humanos e sociais e recusa explicações essencialistas e naturalizantes; enfim, um olhar que se move por uma força imaginativa e articula as relações entre biografias e história, como princípio heurístico do conhecimento social, visão consolidada na literatura sobre ensino de Sociologia.

Com isso, não sugerimos secundarizar a Teoria Social. Ao contrário, para produzirmos essa atitude cognitiva nos alunos desse segmento do ensino, precisamos levá-los a conhecer os objetos do mundo social a partir de um confronto com a realidade social. No entanto, o contato com a realidade social, pela análise de 
objetos e diálogo com sujeitos do mundo social, somente será significativo em situação pedagógica se dirigido pelo discurso científico das Ciências Sociais, orientado, portanto, pela teoria social e por seus conceitos. Partimos dos conceitos que desejamos ensinar.

Recorremos mais uma vez a Raymond Williams (1979), para quem a consciência se constitui por um processo de socialização específico, pela participação dos indivíduos em grupos culturais, dando origem ao que ele denominou por estrutura de sentimentos, isto é, os sentidos que consignamos à experiência do vivido e que se constituem como resistência e oposição à id eologia e à prática hegemônicas e que não são simples reflexos ou espelhos da estrutura social. Mudanças nas estruturas de sentimentos são fundamentais para que alterações na estrutura social tenham vez. Mais importante do que os conceitos, nesse caso, é a capacidade de produção de sentido e de compreensão da experiência vivida, o que pode ser facilitado pela compreensão conceitual e teórica.

Incorporar os recentes estudos e debates sobre gênero, dar a conhecer as disputas e tendências a que estão relacionados e o significado político primário do desenvolvimento do tema - sua história, seus enlaces e suas expressões - é permitir que o aluno do Ensino Médio se aproprie de ferramentas intelectuais, reorganize sua cognição e domine uma linguagem fundamental para a reconstrução de relações sociais de dominação. O contrário, no entanto, que é reduzir a questão de gênero à perspectiva da convivência e da tolerância, uma questão de direito acima de tudo, ou abordá-la de um ponto de vista conceitual formal, mesmo na roupagem das "competências", é tornar raso e estéril esse conteúdo e deixar de dotar de melhor inteligibilidade o mundo vivido por esses alunos: um triste desdobramento para a disciplina.

Como cientistas sociais, acreditamos que gênero não deveria ser um conceito relegado a um tema transversal, mas uma ferramenta de análise presente integralmente na disciplina Sociologia. É verdade que, em grande medida, a inclusão de certos temas e conceitos na sala de aula obedece menos a documentos oficiais do que aos livros didáticos adotados e, principalmente, à seleção de interesses 
UMA PALAVRA SOBRE O SILÊNCIO: CONTEÚDOS DE GÉNERO PARA SOCIOLOGIA

NOS PCN, OCN E BNC

Andréa Osório

Flávio Sarandy

docentes. Desse modo, a presente análise não corresponde às práticas pedagógicas contextualizadas, mas apenas aos documentos que deveriam embasar essas práticas, assim como deveriam, os documentos, embasar a confecção de livros didáticos: se esses documentos fossem mais explícitos na inclusão de estudos de gênero nas disciplinas de humanidades, acreditamos que os autores de livros didáticos os seguiriam, em vez de abordarem tais estudos segundo sua inclinação pessoal.

Não se trata, por outro lado, de desmembrar a Orientação Sexual dos debates de gênero, mas de retirar dessa zona de penumbra, que são os Temas Transversais, uma categoria (gênero) sobre a qual acreditamos que deveria ser lançada mais luz, especialmente a partir de eventos recentes que levantam a intensa necessidade de uma ampliação do debate, a saber: a crescente mobilização feminina no país a respeito de questões como a violência contra a mulher e o aborto; as críticas que o ENEM 2015 recebeu por incluir a violência contra a mulher como tema da redação e Simone de Beauvoir em uma questão fechada ${ }^{4}$; projetos de lei na Câmara dos Deputados que impõem censura aos docentes nas salas de aula e aos conteúdos de gênero nas escolas ${ }^{5}$; entre outros eventos perturbadores, que incluem moções e leis municipais misóginos, homofóbicos e transfóbicos.

Se gênero fosse incorporado como uma questão típica da Sociologia (embora não apenas), necessária e atual, teórica e metodologicamente embasada, em vez de um programa de tolerância à diferença, poder-se-ia ampliar o escopo para a interseção com estudos de geração, relações raciais e etnicidade, entre outros, trazendo novas questões e epistemes para as disciplinas escolares. Seria incalculável o ganho intelectual, ético e político de um programa educacional bem

4 <http://brasil.elpais.com/brasil/2015/11/09/opinion/1447075142_888033.html?id_externo_rsoc=FB_C M>. Acesso em: 16 nov. 2015.

5 Disponível em: <http://educacaointegral.org.br/noticias/projeto-de-lei-preve-prisao-dedocente-que-falar-sobre-ideologia-de-genero/>. Acesso em: 16 nov. 2015. 
UMA PALAVRA SOBRE O SILÊNCIO: CONTEÚDOS DE GÉNERO PARA SOCIOLOGIA

NOS PCN, OCN E BNC

Andréa Osório

Flávio Sarandy

estruturado que não assumisse, ainda que tacitamente, a visão do aluno do Ensino Médio como incapaz ou desinteressado nessas discussões.

\section{REFERÊNCIAS}

ALTMANN, Helena. Orientação sexual nos Parâmetros Curriculares Nacionais. Revista Estudos Feministas, Florianópolis, v. 9, n. 2, p. 575-585, 2001.

BRASIL. Lei de Diretrizes e Bases da Educação Nacional. Lei n. 9394, de 20 de dezembro de 1996. Estabelece as diretrizes e bases da educação nacional. Brasília, DF, 1996.

BRASIL. Lei n. 11.684, de 2 de junho de 2008. Altera a Lei de Diretrizes e Bases da Educação Nacional, Lei n. 9394 de 1996. Brasília, DF, 2008.

BRASIL. Ministério da Educação. Parâmetros Curriculares Nacionais: apresentação dos Temas Transversais. Brasília: MEC, 1998.

BRASIL. Ministério da Educação. Parâmetros Curriculares Nacionais: Ensino Médio. Brasília: MEC, 1998.

BRASIL. Ministério da Educação. Orientações Curriculares para o Ensino Médio. v. 3. Brasília: MEC/SEB, 2006.

BRASIL. Ministério da Educação. Base Nacional Comum Curricular. Brasília: MEC, 2015.

BUTLER, Judith. Problemas de gênero: feminismo e subversão da identidade. Rio de Janeiro: Civilização Brasileira, 2003.

GANDELMAN, Luciana M. Gênero e ensino: parâmetros curriculares, fundacionalismo biológico e teorias feministas. In: ABREU, Martha; SOIHET, Rachel (Org.). Ensino de História: conceitos, temáticas e metodologia. Rio de Janeiro: Casa da Palavra, 2003. p. 209-220.

LOURO, Guacira Lopes. Teoria queer: uma política pós-identitária para a educação. Revista Estudos Feministas, Florianópolis, v. 9, n. 2, p. 541-553, 2001.

SCOTT, Joan. Gênero: uma categoria útil para análise histórica. Mimeo. SOS Corpo. Tradução de Christine Rufino Dabat e Maria Betânia Ávila. s/d, s/l [1989]. 


\section{INTER-LEGERE}

UMA PALAVRA SOBRE O SILÊNCIO: CONTEÚDOS DE GÊNERO PARA SOCIOLOGIA NOS PCN, OCN E BNC

Andréa Osório

Flávio Sarandy

WILLIAMS, Raymond. Politics and Letters: interviews with New Left Review. Londres: Verso, 1979. 